\title{
Conservation planning and Indigenous governance in Australia's Indigenous Protected Areas
}

Running Head: Conservation planning in Indigenous Protected Areas

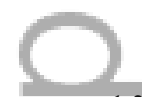

Lee Godden ${ }^{1,2}$ and Stuart Cowell ${ }^{3}$

1. Melbourne Law School, The University of Melbourne, Victoria, 3010

2. Correspondence: lcgoddden@unimelb.edu.au

3. Conservation Management Pty Ltd, Hobart, Tasmania, 7000

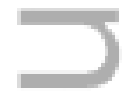

Author contributions: LG, SC conceived, researched and wrote the paper

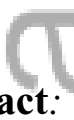

\begin{abstract}
:
Indigenous Protected Areas (IPAs) recognise that 'country' constitutes land and waters that have enduring cultural, social and economic linkages for Aboriginal and Torres Strait Islander peoples that extend over millennia, and which are critical to sustainable Indigenous futures. Within Australia's conservation system, Indigenous Protected Areas become part of the National Reserve System when Indigenous peoples voluntarily announce their intention to manage 'country,' in accordance with their law, custom and culture, and consistently with national and international conservation guidelines. The National Reserve System requirement is that land is managed 'in perpetuity' which highlights a potential tension between with the conservation goals and the voluntary character of Indigenous Protected Areas. Ecological
\end{abstract}

This is the author manuscript accepted for publication and has undergone full peer review but has not been through the copyediting, typesetting, pagination and proofreading process, which may lead to differences between this version and the Version of Record. Please cite this article as doi: $10.1111 /$ rec.12394

This article is protected by copyright. All rights reserved. 
restoration in Indigenous Protected Areas also raises contested ideas about what is 'natural', the relevant 'baseline' for restoration and what are the objectives to be achieved - ecological or cultural sustainability? Experience from Healthy Country Planning in Indigenous Protected Areas indicates that restoration of Traditional Owner decision-making, as well as respectful use and the valuing community knowledge, is central to the sustainability of outcomes. Ecological restoration is most effectively achieved by restoring governance processes that support Indigenous peoples given the inseparability of cultural, social, economic and ecological objectives.

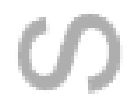

Key words: National Reserve System, Healthy country, Aboriginal, Traditional knowledge

\section{Implications for Practice:}

- Restoration must engage with Aboriginal traditional knowledge and practices when defining what is to be 'restored' and avoid locking in a static indigenous culture.

- The Healthy Country model aims to protect and provide for the respectful utilisation of traditional knowledge in ecological restoration.

- Effective conservation planning and ecological restoration in Indigenous Protected Areas must support Aboriginal communities though decision-making and governance for protected area planning.

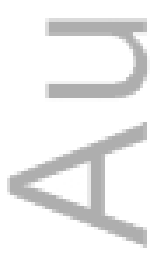




\section{Introduction}

Indigenous Protected Areas are representative of a significant change in conservation planning and management within Australia over the last two decades (Jaireth \& Smyth 2003). Indigenous Protected Areas occur over areas of land or sea held by traditional owners where the Indigenous communities have entered into an agreement with the Australian Government to promote biodiversity and cultural resource conservation. The focus on indigenous participation and governance distinguishes Indigenous Protected Areas as a significant shift away from a wilderness model for protected areas (Godden 2002). The new paradigm, evident in IPAs acknowledges that 'country' constitutes land and waters that have enduring cultural, social and economic linkages for Aboriginal and Torres Strait Islander peoples.

Those connections extend over millennia and are critical to sustainable Indigenous futures (ALRC 2015). The transition is neither comprehensive nor is its implementation unproblematic.

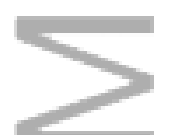

Indigenous Protected Areas have a specific designation within the legal framework for conservation management within Australia. A protected area is defined by Australian governments as "a clearly defined geographical space, recognised, dedicated and managed through legal or other effective means to achieve the long-term conservation of nature with associated ecosystem services and cultural values" (Australian Government 2016). An Indigenous Protected Area on land will become part of the National Reserve System when Indigenous 'landowners' voluntarily declare their intention to manage their 'country', in accordance with traditional law, custom and culture, and consistent with national reserve requirements and International conservation guidelines (Dudley 1994). For Indigenous 
Protected Areas on sea country, there is not the same correlation with the national reserve system given the flux in the status of the marine reserve system (Butterly 2013). There is significant variation in the forms of tenure and rights that comprise Aboriginal and Torres Strait Islander 'ownership' across the Australian continent (Tehan 2003). A prerequisite for terrestrial Indigenous Protected Areas is that the underlying traditional ownership has been 'formalised.' Sea-country Indigenous Protected Areas differ, as an underpinning tenure may be absent; thereby requiring indigenous groups to actively build networks to support culturally-based conservation measures.

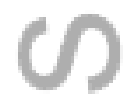

The establishment of Indigenous Protected Areas was preceded by various forms of comanagement or joint management with Aboriginal and Torres Strait Islander communities over their traditional land and waters (Bauman \& Smyth 2007). These moves to 'jointly' manage country were given impetus by legal reforms, including the recognition of Native Title in 1992 (Bauman et al. 2013) and international human rights developments. Over the same time frame, ecological restoration has progressively developed within Australia, from discrete programs such as Landcare to a more comprehensive approach to conservation (McDonald \& Williams 2009).

While the two trends coalesce around Indigenous Protected Areas, each brings a particular perspective and set of knowledge practices to conservation planning and management that may not necessarily be congruent. Indigenous Protected Areas have a unique status within Australia's conservation system, while aligning also with the National Reserve System (NRS) 
for biodiversity conservation. The NRS is regarded as the "nation's natural safety net against our biggest environmental challenges" (Australian Government 2014).

Well-established protocols and programs such as 'Healthy Country Planning' now exist, which build on earlier 'co-management' and 'partnerships' approaches but which seek to institute a stronger model of governance of Indigenous Protected Areas by indigenous communities (Butterly 2013). Attention is now being directed to supporting capacity for Aboriginal and Torres Strait Islander communities to actively govern Indigenous Protected Areas. Challenges still remain in fully incorporating ecological restoration goals into broadlyconceived indigenous governance of protected areas. Experience from Healthy Country Planning indicates that restoration of Traditional Owner decision-making, as well as respectful use and the valuing community knowledge is central to the sustainability of outcomes in Indigenous Protected Areas.

This article briefly charts the reorientation in conservation planning for protected areas in Australia, before examining the legal structures that enable and support Indigenous Protected Areas in Australia. The article then turns to the challenges of conservation planning and ecological restoration in Indigenous Protected Areas. A ‘restoration' model for IPAs raises contested ideas about what is 'natural,' the relevant 'baseline' for restoration and engenders debate about the objectives to be achieved-ecological or cultural sustainability? Secondly, there are significant resourcing and capacity building requirements to support conservation in Indigenous Protected Areas, particularly where proactive ecological restoration is planned or where traditional owners have been displaced from 'country' in the past. Finally, it raises the 
challenge of how best to support and build Aboriginal and Torres Strait Islander community governance and decision-making around multi-faceted objectives for IPAs.

\section{From Wilderness Ideals to Indigenous Protected Areas}

Protected areas grew from a preservationist ideal of nature where the impulse was to separate humans and nature to protect a sublime nature as 'wilderness' (Colchester 1997). Early World Conservation Union (IUCN) guidelines for protected areas emphasised this separation. Protected areas subsequently were considered to be "essential for the conservation of biological diversity" (Ghimire \& Pimbert 2013). Widespread criticism of the wilderness model and its effects upon communities that live within or depend upon protected areas led to significant changes in conservation philosophy (Dudley 2013). Even so, a constellation of views about 'conservation' often will exist among members of indigenous communities (Butterly 2013).

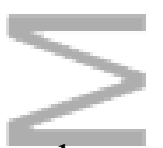

The early management paradigms for Australia's protected areas and national parks were strongly influenced by the initial international approach. When combined with the legal position that Australia was a settled colony, it excluded consideration of Aboriginal and Torres Strait Islander peoples' relationships with traditional land and waters (Godden 2002). Ecology, with its origins in colonial science, reinforced the purported 'primitiveness' of Australia's Indigenous Peoples casting them as either 'Noble Savages' and even at times as 'mega fauna' in an ecosystem. The European 'property' perspective predisposes toward dominance over land and water (now arguably transmuted to softer 'management' concepts). This approach contrasts with Aboriginal peoples' obligations to country: 
"The social practices that constitute the expression of proprietary interests are embedded in everyday life and its patterning by kinship, descent, spiritual metaphors and both individual and community history. Knowledge of both the biophysical and spiritual landscape is essential to the good standing, authority and power of a landowner, particularly an Elder, to represent the interests of the group in the affairs of the territory." (Langton 2010) Australian law and conservation frameworks have belatedly recognised these connections to country, the attendant obligations and the need for country to form the foundation for social, economic and cultural sustainability for Aboriginal and Torres Strait Islander communities (Altman 2014). In 2005 Tucker noted "[t]here are, however, few practical examples of the parallels between 'healing country' (restoration) and 'healing relationships' (reconciliation). He advocated consideration of the intertwined concepts: reconciling the relationships that Australian society has with the land and its indigenous inhabitants, as well as, 'restoring new ecological balance to the country which nurtures and sustains all cultures" (Tucker 2005).

\section{Indigenous Protected Areas and the National Reserve System}

A residual silo approach to 'environment' and Indigenous Peoples still is evident in some aspects of the National Reserve System. The National Reserve System and 'protected areas' are generally governed under the Environment Protection and Biodiversity Conservation Act 1999(Cth). The NRS objectives reflect an ecological perspective:

“The National Reserve System is Australia's network of protected areas, conserving examples of our natural landscapes and native plants and animals for future generations. Based on a scientific framework, it is the nation's natural safety net against our biggest environmental challenges" (Australian Government 2014). 
"Australian ecosystems have been shaped by Aboriginal peoples for tens of thousands of years prior to the arrival of Europeans" (McDonald \& Williams 2009). Thus the 'fit' between robust recognition of Aboriginal and Torres Strait Islander governance of traditional land and waters and the priorities of conservation planning under the NRS (including marine reserves) are part of the complex challenges facing Indigenous Protected Areas. Significantly, it is estimated that $30 \%$ of Australia is held under indigenous tenure or 'rights' (Altman 2014). Native title claims to offshore areas, and other forms of agreement-making with Aboriginal and Torres Strait Islander peoples around sea country, have the potential to significantly expand that coverage. The NRS objectives to date do not express the enhanced role of Indigenous communities in land and sea management that these changes to tenure reflect. Indigenous Protected Areas are an important factor in addressing this gap.

\section{Ecological Restoration and Conservation Planning}

Broadly speaking, ecological restoration efforts in Australia seek to address the 'reduction in the condition and area of most ecosystems' due to modern post-industrial society (McDonald \& Williams 2009). Measures are designed to counter the degradation of endemic ecosystems, the loss of habitat and the decline in species to re-establish, functional ecosystems'(Clewell et al. 2000). Expanding human populations, invasive species and climate change make the challenge of restoring species assemblages and ecosystem processes in highly degraded landscapes difficult. While ecological restoration applies at many different sites and scales, protected areas offer an obvious location when seeking to restore ecosystems. 
Changes in approaches to conservation planning in Australia reflect broader changes in economic, political and social institutions and processes. As noted by Moorcroft et al (2012) “[h]istorically, conservation planning in Australia has been embedded in a specific cultural context that privileges Western science, linear views of time and bounded notions of space, and asserts particular assumptions about the separation of nature and culture, resource management and human intervention."

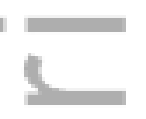

Conservation planning now needs to consider inter alia integration of social, cultural, economic and natural factors; inequalities of wealth and gender; development of social, cultural and natural capital; devolution of decision making; and managing ecosystems in a human context (Campbell \& Fainstein 1996; Maltby 1997; Mercer 2000; Selman 1996 in Lockwood 2016).

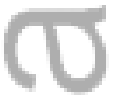

These changes are most evident in the development of plans for Indigenous Protected Areas, where "planning can achieve positive outcomes for Indigenous groups if it is communitybased, and centred on community objectives, capabilities and knowledge systems rather than those imposed by another party" (Lane 2006 in Moorcroft et al 2012). Increasingly, indigenous law and practice is guiding the development of conservation planning; fostering legal pluralism and greater intercultural understanding - a feature clearly evident in many sea country Indigenous Protected Areas (Butterly 2013).

This article is protected by copyright. All rights reserved. 


\section{National Reserve System and Indigenous Protected Areas}

The Australian government established a 'comprehensive, adequate and representative' protected area system, which later evolved into the NRS. The NRS includes more than 10,000 protected areas covering almost 18 per cent of Australia; comprising Commonwealth, state and territory Crown land and reserves, Indigenous lands and protected areas held by non-profit conservation organisations, and ecosystems protected in perpetuity on private land (Australian Government 2014). In offshore areas, the marine reserve system is of more development. The incorporation of privately-owned land and Indigenous Protected Areas has been driven in part by the need enhance the comprehensiveness of the NRS. Land and sea that come under various forms of traditional ownership and which are protected as Indigenous Protected Areas comprise almost 7 per cent of Australia (Australian Government 2014), and $40 \%$ of the National Reserve System. The extent of Indigenous Protected Areas within Australia are shown in Figure 1 below.

\section{Legal Framework for Indigenous Participation in Conservation}

Legal change has been an important driver for enhanced indigenous participation in environmental management. The pre-native title era was characterised largely by the exclusion of indigenous communities from 'formal' conservation models apart from land management and planning connected with statutory land rights schemes and some ad hoc involvement in national parks, World Heritage. Cultural heritage legislation was significant in regulating land access and instituted site specific protections (Godden 2002). Many initiatives for indigenous involvement in environmental management were limited to a consultative role. 
A series of co-management arrangements were developed by federal, territory and state governments seeking to involve Indigenous people in government managed protected areas in Australia. Co-management models include Kakadu, Uluru Kata-Tjuta and Nitmiluk (Katherine Gorge) National Parks in the Northern Territory. Most co-managed national parks are implemented through a lease back model where Aboriginal groups, have their traditional country returned on condition that they lease it back to government conservation agencies as protected areas (Smyth 2011).

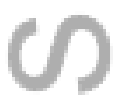

While Aboriginal and Torres Strait islander peoples have long cared for country under their law, tradition and custom, the recognition of native title in Mabov Queensland, (No 2) in 1992 gave stronger legal weight to indigenous peoples' involvement in the protection of country. Native title also gave effect to indigenous governance of land and waters, through the concept of connection in the Native Title Act 1993(Cth). Despite not fully meeting the aspirations of indigenous communities, Native title gave indigenous people "a seat at the table" to care for country (Dodson \&Strelein 2001; Bartlett 2015).

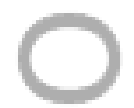

The growing number of determinations of native title has driven a correlative expansion in indigenous environmental governance. Expansion has occurred via agreements, often as Indigenous Land Use Agreements (ILUA) under the Native Title Act 1993 (Cth). Agreementmaking has assumed central importance in determining how Aboriginal and Torres Strait Islander peoples' relationship with the 'conservation' and ecological restoration sector is managed (Smyth 2011). Agreement-making, while offering opportunities for indigenous 
communities in environmental governance (Bauman \& Smyth 2007) may not deal effectively with the pervasive exclusion of indigenous peoples (Altman \& Kerins, 2012, Altman 2014). Indigenous Protected Areas have the potential to 'close the gap.'

\section{Conservation and Indigenous Protected Areas}

Indigenous Protected Areas rest on a prerequisite of Aboriginal 'ownership' of land and waters to be protected. For inclusion in the IPA program Aboriginal and TSI communities commit to manage their land to maintain biological diversity according to internationally recognised land management categories defined by World Conservation Union (IUCN). Aboriginal communities must already have native title or other forms of 'ownership' over areas that are brought voluntarily into the IPA Programme. Once an IPA has been declared, following initial funding discussions and management planning, subsequent investment proposals can be made to implement a plan of management. IPAs offer resources for land management without the loss of autonomy that may be associated with co-management or joint management schemes.

\section{Conservation planning in Indigenous protected areas}

In the past few years conservation planning in Indigenous Protected Areas has moved from specific tenüre-based approaches to more holistic country planning, in what is frequently referred to as a tenure-blind approach. The focus in such an approach is on indigenous governance rather than the scope of planning being determined with primary reference to the nature of the underlying land tenure. Such a model is exemplified by sea country Indigenous 
Protected Areas. In these approaches, the establishment of Indigenous Protected Areas has become a tenure-based 'strategy' within country plan. One approach (of many) used in planning for country and IPAs is the Healthy Country Planning methodology. Healthy Country Planning (HCP) is an adaptation of the Open Standards for the Practice of Conservation (Open Standards) being used and adopted by Aboriginal land management teams across Australia. The Open Standards are and adaptive management tool that "bring[s] together common concepts, approaches, and terminology in conservation project design, management, and monitoring in order to help practitioners improve the practice of conservation" (CMP 2013). The Open Standards are "increasingly being used in landscape and property conservation planning projects throughout Australia, including well-known landscape projects (e.g. Gondwana Link), and as the primary planning tools for a number of ENGOs. The tools are also increasingly being adapted to support Indigenous community use" (Moorcroft et al 2012)

Although built around biodiversity conservation, the tools of the Open Standards are able to be translated for use into other contexts, particularly those where biodiversity conservation is intertwined with the culture and livelihood of local communities. HCP is consistent with the Open Standards, but with language and some of the facilitation approaches and tools tailored to community needs, focusing on participation and engagement and the inclusion of community and traditional knowledge and priorities. HCP follows five main steps, each with a number of sub-steps that are illustrated in the Figure 2 below:

1. Deciding what the plan is about: clarifying what the plan will focus on, including vision, scope, targets (assets), threats, \& stakeholders 
2. Making the Plan: Develop strategies, actions \& monitoring plans.

3. Doing \& Monitoring the work: Putting into practice our actions

4. Deciding if the plan is working: Review of progress \& making changes if needed

5. Telling ourselves \& others: reporting on our progress

The key additional features of Healthy Country Planning are:

- Planning on Country - Being on country is the appropriate place to talk about country

- Using Indigenous Governance - Adapting planning process structure to suit local context, co-development of approach

- Flexible time \& regular feedback — Not rushing the planning process \& being flexible with dates

- Using appropriate terms \& language — Like all planning systems, Open Standards language has specific terms that can be adapted to suit the context

- Restoration of Traditional Owner decision making — using and valuing community knowledge

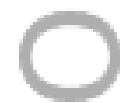

By ensuring the process is controlled by Traditional Owners and incorporates Indigenous language and core concepts means that Healthy Country Planning, like many approaches in this space, respects and supports community integrity (Moorcroft 2012). In turn this demonstrates that "indigenous controlled planning can shape a more equitable intercultural conservation" (Moorcroft et al 2012). 


\section{IPA Management: What have we learnt?}

Thus as is increasingly demonstrated by the Country Needs People (2016) restoring culturally-based management can support other restoration goals - ecological, as well as social and cultural. Yet, if Indigenous Protected Areas are to fulfil the function of offering a more equitable form of intercultural conservation and ecological restoration, then it is vital to continue to build governance capacity for Aboriginal and Torres Strait Islander peoples.

Entry into an indigenous protected area arrangement or similar model is a significant, tangible outcome for traditional owners from many native determinations across Australia: for some groups it may be the only substantial outcome. The Native Title Act 1993 (Cth) provides traditional owners with a negotiating position for entering into agreements, but native title groups face ongoing challenges in the post-determination landscape. Strengthening governance capacity for the group should commence well before the traditional owners have a native title determination. Moreover, currently, few Native Title Bodies Corporate, (the entity which exercises governance powers on behalf of people holding native title after a native title determination) are being adequately supported to manage well. Further, many groups have to contend with, "the general inflexibility of the Native Title Act and the lack of institutional and resource support for Registered Native Title Bodies Corporate" (Bauman et al. 2013). These constraints may inhibit the achievement of the wider goals embedded within the restoration of culturally-based land and sea management.

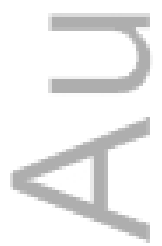




\section{Future Challenges}

Indigenous Protected Areas, while part of the national reserve system, also need to serve longer term goals for Aboriginal and Torres Strait Islander peoples. The challenge for ecological restoration efforts is not to lock in a model that gives priority to either ecological values or static 'traditional' management but rather to adopt a flexible approach that allows for 'bottom up' indigenous community management. Ideally, IPAs offer an opportunity to build collaborative governance structures to achieve long-term improvements in indigenous social capacity, and environmental and economic well-being. The conjoining of ecological protection and Indigenous community decision-making and governance for biodiversity management in this way can achieve long term sustainability (Wallis et al. 2012).

\section{Acknowledgements}

An earlier version was delivered at The Restoration Dialogues Workshop 3-4 November 2015. The authors thank Professor Ted Lefroy and Professor Ben Richardson for organising that workshop. The authors also thank the reviewers for their constructive comments and suggested improvements.

\section{LITERATURE CITED}

Altman J (2014) The political ecology and political economy of the Indigenous land titling revolution in Australia. M ori Law Review Indigenous Law Speaker Series: March 2014

Altman J, Kerins S (2012) People on Country, Vital Landscapes, Indigenous Futures. The Federation Press, Annadale NSW

This article is protected by copyright. All rights reserved. 
Australian Law Reform Commission (ALRC) (2015) Connection to Country: Review of the Native Title Act 1993 (Cth) (ALRC Report 126).

https://www.alrc.gov.au/publications/alrc126 (accessed 8 March 2016)

Australian Government (2014) National Reserve System Protected Area Requirements.

Department of the Environment http://www.environment.gov.au/land/nrs (accessed 8

March 2016)

Australian Government (2016) Indigenous Protected Areas. Department of the Environment http://www.environment.gov.au/land/indigenous-protected-areas (accessed 8 March

\section{6)}

Bartlett R (2015) Native Title in Australia. LexusNexus Butterworths, Sydney

Bauman T, Smyth D (2007) Indigenous Partnerships in Protected Area Management in Australia: Three case studies. AIATSIS, Canberra

Bauman T, Haynes C, Lauder G (2013) Pathways to the co-management of protected areas and native title in Australia, Discussion Paper, No. 32. AIATSIS Canberra

Butterly L (2013) Changing Tack: Akiba and the Way Forward for Indigenous Governance of Sea Country. Australian Indigenous Law Review 17:2-22

Campbell S, Fainstein S (eds) (1996) Readings in planning theory. Blackwell, Oxford.

Clewell A, Rieger J, Munro J (2000) Guidelines for Developing and Managing Ecological

Restoration Projects. Society of Ecological Restoration

http://ser.org/resources/resources-detail-view/guidelines. (accessed 8 March 2016)

Colchester M (1997) Salvaging nature: Indigenous Peoples and Protected Areas in Ghimire K, Pimbert M (eds) Social Change and Conservation Environmental Politics and Impacts of National Parks and Protected Areas (2013) Earthscan, London

This article is protected by copyright. All rights reserved. 
Conservation Measures Partnership (CMP). Open Standards for the Practice of Conservation,

Version 3.0. www.conservationmeasures.org. (accessed 8 March 2016)

Country Needs People (2016) http://www.countryneedspeople.org.au/ (accessed 8 March 2016)

Dodson M, Strelein L (2001) Australia's nation-building: renegotiating the relationship between indigenous peoples and the state. University of New South Wales Law

Journal 24:826-39

Dudley N (1994) Guidelines for applying protected area management categories. IUCN,

Switzerland

Dudley N (ed) (2013) Guidelines for Applying Protected Area Categories. Gland,

Switzerland, IUCN http://www.iucn.org/about/work/programmes/gpap_home (accessed 10 February 2016)

Ghimire K, Pimbert M (eds) Social Change and Conservation Environmental Politics and Impacts of National Parks and Protected Areas (2013) Earthscan, London

Godden L (2002) Indigenous Heritage and The Environment: Legal Categories are Only One Way of Imagining the Real. Environmental and Planning Law Journal 19:258-266 Jaireth H, Smyth D (eds) (2003). Innovative governance: indigenous peoples, local

communities, and protected areas. Ane Books, New Delhi

Lane M (2006) The role of planning in achieving Indigenous land justice and community goals. Land Use Policy 23:385-394

Langton M (2010) The estate as duration: 'Being in place' Godden L and Tehan M (eds) Comparative perspectives on communal lands and individual ownership: Sustainable futures, Routledge, London

This article is protected by copyright. All rights reserved. 
Lockwood M (2016) Introduction to management planning. Notes from KGA531 Protected Area Management Plans. University of Tasmania

Maltby E (1997) Ecosystem management: the concept and the strategy. World Conservation $3: 3-4$

McDonald T, Williams J (2009) A perspective on the evolving science and practice of ecological restoration in Australia. Ecological Management \& Restoration 10:113-125

Mercer D (2000) A question of balance: natural resources conflict issues in Australia (3rd ed). Federation Press, Sydney

Moorcroft H, Ignjic E, Cowell S, Goonack J, Mangolomara S, Oobagooma J, Karadada R, Williams D, Waina N (2012) Conservation planning in a crosscultural context: the Wunambal Gaambera Healthy Country Project in the Kimberley, Western Australia. Ecological Management \& Restoration 13:16-25

Selman P (1996) Local sustainability: managing and planning ecologically sound places.

Chapman, London

Smyth D (2011) Indigenous land and sea management: a case study. Australian Government Department of Sustainability, Environment, Water, Population and Communities on behalf of the State of the Environment 2011 Committee, Canberra

Tehan M (2003) A Hope Disillusioned, An Opportunity Lost? Reflections on Common Law Native Title and Ten Years of the Native Title Act. Melbourne University Law Review $27: 523$

Tucker N (2005) Healing country and healing relationships. Ecological Management \& Restoration 6:83-84

This article is protected by copyright. All rights reserved. 
Wallis R, Wallis A, Picone A (2012) After 80 years absence, Wuthathi people plan for the return and management of ancestral homelands on Cape York Peninsula. Ecological Management \& Restoration 13:81-84

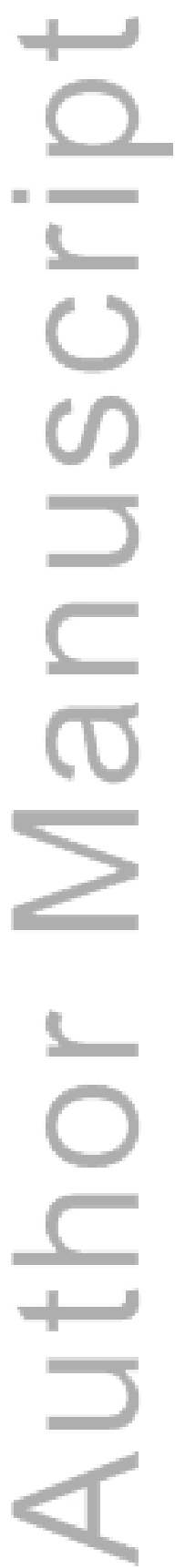

This article is protected by copyright. All rights reserved. 
Figure 1: Australian Indigenous Protected Areas 2015
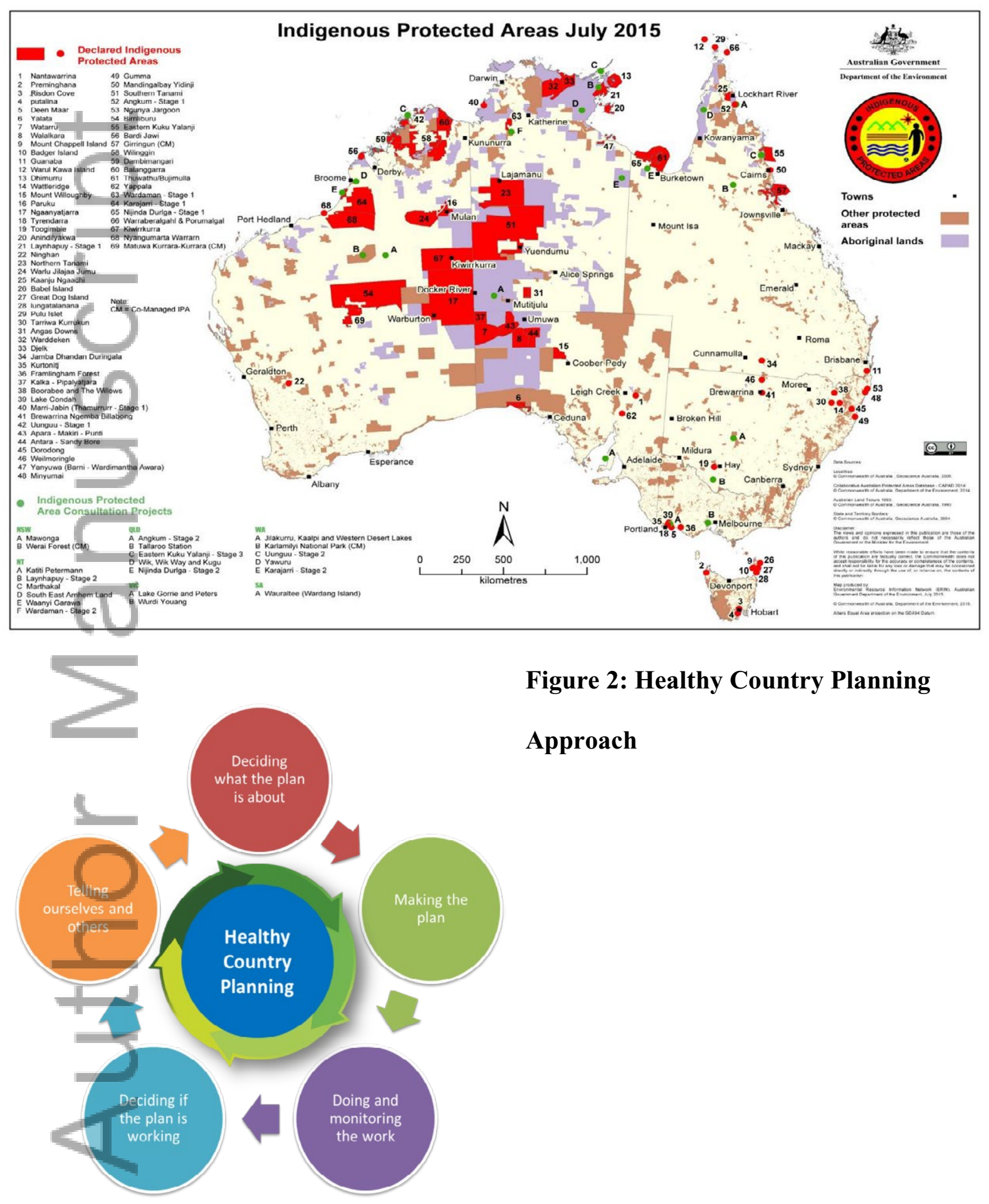

Figure 2: Healthy Country Planning

Approach

This article is protected by copyright. All rights reserved. 


\section{University Library}

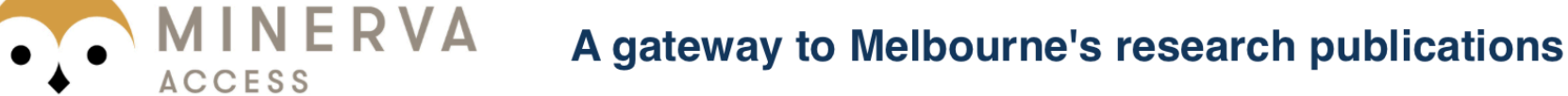

Minerva Access is the Institutional Repository of The University of Melbourne

Author/s:

Godden, L;Cowell, S

Title:

Conservation Planning and Indigenous Governance in Australia's Indigenous Protected Areas

Date:

2016

Citation:

Godden, L. \& Cowell, S. (2016). Conservation Planning and Indigenous Governance in Australia's Indigenous Protected Areas. Restoration Ecology, 24 (5), pp.692-697. https:// doi.org/10.1111/rec.12394.

Persistent Link:

http://hdl.handle.net/11343/290777 